\title{
Diversity of Antibiotic Resistance Among Bacteria Isolated from Sediments and Water of Carp Farms Located in a Polish Nature Reserve
}

\author{
Marta Piotrowska, Marzenna Rzeczycka, \\ Rafal Ostrowski, Magdalena Popowska* \\ Department of Applied Microbiology, Institute of Microbiology, Faculty of Biology, \\ University of Warsaw, Warsaw, Poland
}

Received: 26 February 2016

Accepted: 30 August 2016

\begin{abstract}
The present study collected bacterial samples from water and bottom sediments from fish farms located in a nature reserve area in Poland with no recorded history of antibiotic use. The aim of the study was to determine the initial states of tetracycline, streptomycin, and erythromycin resistance before a potential increase of intensive aquaculture and application of antimicrobial agents in that region. With this in mind, the diversity and antibiotic resistance phenotypes and genotypes of isolates from the bottom sediments and water in five of the 13 fish ponds in Raszyn were evaluated. A total of 58 (sediment, $n=24$; water, $n=$ 34) non-repetitive and non-susceptible isolates were affiliated to 14 genera. Among the sediment isolates, Pseudomonas spp. and Bacillus spp. were isolated most frequently, and from the water, Stenotrophomonas spp. and Pseudomonas spp. Phenotypically resistant isolates selected by disk diffusion were further screened by polymerase chain reaction (PCR) and amplicon sequencing. The isolates derived from the water showed a greater percentage of phenotypically resistant isolates to each of the three antibiotics. The most common tetracycline resistant genes detected in isolates from both the water and sediment were $\operatorname{tet}(\mathrm{A}), \operatorname{tet}(\mathrm{T}), \operatorname{tet}(\mathrm{W})$, and $\operatorname{tet}(34)$. On the other hand, the genes $\operatorname{tet}(\mathrm{X}), \operatorname{tet}(\mathrm{H}), \operatorname{tet}(\mathrm{M})$, and $\operatorname{tet}(\mathrm{BP})$ were the most frequent among sedimentary isolates, while $\operatorname{tet}(\mathrm{B}), \operatorname{tet}(\mathrm{C}), \operatorname{tet}(\mathrm{D})$, and $\operatorname{tet}(32)$ were prevalent in aquatic isolates. The most prevalent streptomycin resistance genes among the aquatic isolates were $\operatorname{aac}\left(6^{\prime}\right)-I, \operatorname{str}(\mathrm{A})$, and $\operatorname{str}(\mathrm{B})$. The erythromycin resistance genes detected in all isolates included $m \operatorname{sr}(\mathrm{A}), \operatorname{erm}(\mathrm{X}), \operatorname{erm}(\mathrm{V}), \operatorname{erm}(\mathrm{F})$, and $\operatorname{erm}(\mathrm{E})$.
\end{abstract}

Keywords: aquaculture, tetracycline, streptomycin, erythromycin, antibiotic resistance gene

*e-mail: magdapop@biol.uw.edu.pl 


\section{Introduction}

Aquacultures are an intensively developing, fastgrowing food industry. Continuous intensification of fish farming, increasing the risk of disease, has resulted in the need for treatment with antibiotics [1]. Currently, antibiotics officially approved for use in the treatment and prophylaxis of cultured aquatic animals are oxytetracycline, florfenicol, sarafloxacin, erythromycin, and sulfonamides with trimethoprim or ormethoprim [2-4]. This favors the formation of so-called antibiotic pressure and the spread of antibiotic resistance, among others, through the acquisition of antibiotic resistance genes (ARGs) as a result of horizontal gene transfer (HGT) [5]. In particular, bacteria of the genus Aeromonas isolated from fish ponds exhibit resistance to multiple antibiotics, and the resistance genes for these therapeutics are primarily located on mobile genetic elements (MGEs) like plasmids and integrons [6-8]. Many literature data clearly indicate that the ponds in which antibiotics are used are a reservoir of ARGs, and therefore pose a great risk to the health and life of humans [9]. The characteristic bacterial genera in aquacultures found with a high frequency, Aeromonas spp. and Vibrio spp., are responsible for fish diseases. What is interesting is that some of the Aeromonas strains causing disease in humans, as the specific vector, may transfer MGEs carrying resistance genes to pathogenic or opportunistic bacteria in the human microbiome, and thus pose a threat to public health.

Due to the growing requirements of the World Health Organization (WHO) and the need to produce so-called organic food, fish are cultured without using antibiotics for preventive or therapeutic reasons. Examples of such ecological fish ponds are the Raszyn Ponds, which were the object of our research. However, antibiotic free farming is not equivalent to the absence of antibioticresistant bacteria. The presence of antibiotics in the environment is a result of both the activity of natural producers and certain human activities. The primary natural reservoir of microorganisms (bacteria, and fungi) capable of synthesizing antibiotics is the soil. Streptomyces (actinomycetes), which are generally soil bacteria, produce $70 \%$ of the already known antibiotics [10-11]. Antibiotics are produced also by other bacteria, such as Bacillus polymyxa, B. licheniformis, and Pseudomonas fluorescens, and by fungi, e.g., Penicillium chrysogenum, Fusidium coccineum, and F. griseum [12]. Antibiotic producers are also present in the aquatic environment: water and sediments [13] or seawater [14]. The antibiotic producers protect themselves by different mechanisms of resistance: intrinsic and acquired by transferable resistance genes.

Human activities, especially antibiotic usage in breeding pigs, cattle, rabbits, and poultry, are suggested as the main source of antibiotics in the environment [15-17]. Some antibiotics, e.g., oxytetracycline and streptomycin, are also used prophylactically in plant and fruit crops, and beekeeping [18]. The most commonly used antibiotics in agriculture include chlortetracycline, oxytetracycline (widely used in Poland), and erythromycin. Antibiotics are not completely metabolized by livestock, and animal excrement is still often sold by farmers as a fertilizer (manure, slurry) for use in the fields [19]. Antibiotic residues in agricultural soils resulting from both direct applications or indirectly via manure/biosolid amendments can range from a few $\mu \mathrm{g} / \mathrm{kg}$ up to $\mathrm{g} / \mathrm{kg}$ [20]. Antibiotics, especially at low (subinhibitory) concentrations, have a major impact on the selection and promotion of antibiotic-resistant bacteria as they provide a positive selective pressure [2124]. The subinhibitory concentrations of antibiotics induce the transfer of mobile genetic elements through HGT pathways, and therefore enhance antibiotic resistance (also among environmental strains) [16, 25-26]. Many reports indicate that environmental bacteria, even in the absence of selective antibiotic pressure, can carry ARGs identical to those circulating in pathogenic microbiota in clinical environments [27-29]. Simultaneously, it is known that a reduction of the antibiotic load in natural environments may lead to a decrease in the amount of ARGs, e.g., in the absence of antibiotic selective pressure [28, 30]. Depending on the group of antibiotics, the composition of the soil microflora, and prevailing conditions, these drugs may be biodegradable at varying degrees in the environment during different periods of time. Tetracycline degrades by $24 \%$ within 10 to 180 days and erythromycin by $25 \%$ within 30 days, while streptomycin is not degraded up to 30 days after environmental release [20]. Residual antibiotics can affect the composition of the soil and water microbiome [31-32].

The purpose of this study was to determine the level of resistance to tetracycline, streptomycin, and erythromycin, the most commonly used antibiotics in agriculture in Poland. The mechanisms of resistance were detected in bacterial isolates from water and bottom sediments of fish ponds located in a nature reserve area. The results show the initial state before any potential increase of intensive aquaculture and application of antimicrobial agents in the region. These data can be used for comparison with analogous results obtained in studies on antibiotic resistance in fish ponds, in which antibiotics had been used for therapeutic and preventive measures.

\section{Materials and Methods}

\section{Study Area and Sampling}

The study was carried out in carp (Cyprinus carpio) farms located in the Masuria region of Poland called Raszyn Ponds (52॰08`41” N, 20 $55^{\circ} 09^{\prime \prime}$ E; an ornithological nature reserve). They form a complex of 13 ponds remaining under permanent fishery management. All ponds included in the study were characterized by rich biodiversity of plant and animal species, and the carp were raised for food production. All the farms bred carp ecologically, using rainwater (free from synthetic food components) and maintaining environmental values (that is, without any intervention measures in the environment directly adjacent to the ponds). This is extremely 
important, because these sites are a source of diverse plant communities, with a predominance of trees and shrubs, which favors the existence of many species of birds. Next to these areas are apartment settlements and four villages, as well as the busy national highway No. 79, and in the immediate vicinity there are agricultural lands. The methods of feeding, fertilizing, and preventing treatment of fish are in accordance with ecological principles [33]. To reduce the risk of fish disease, slaked lime is applied before filling the ponds, and potassium sulfate is added during the growth period [34].

Bacterial isolates were collected in the period from October 2008 to September 2010 from the bottom sediments and water in five of the fish ponds. Water samples were collected from a depth of approximately $5 \mathrm{~cm}$ below the surface, while sandy and loamy bottom sediments were sampled at a $1 \mathrm{~m}$ distance from the shore, two days after pond drainage. Probes were collected from two different sites within each pond, and were subsequently pooled in a single sample. The samples were collected using plexiglass tubes that were then placed into sterile glass flasks (transported to the laboratory in an ice cooler and analyzed within 1-2 days or stored at $4^{\circ} \mathrm{C}$ ). Only the top $5 \mathrm{~cm}$ of the sediment cores were prepared for analyses.

\section{Quantification and Characterization of Microorganisms}

Several tests were performed to quantify and characterize the microorganisms from the bottom sediments and water. Water samples $(100 \mathrm{~mL})$ were 10 fold diluted in physiological saline (PS) $(0.9 \%$ [wt/vol] $\mathrm{NaCl}$ ), and $0.1-\mathrm{mL}$ aliquots were plated on appropriate culture media. Each sediment sample of approximately $0.1 \mathrm{~g}$ was mixed with $0.9 \mathrm{~mL}$ of sterilized PS. Samples were serially diluted 10, and 100-fold for inoculum preparation and $0.1 \mathrm{~mL}$ were plated on appropriate culture medium. The number of viable, culturable microorganisms from both the environments was evaluated by inoculating R2 Agar (Graso Biotech, Starogard Gdanski, Poland) or M9 Agar (Sigma-Aldrich). The number of endosporeforming bacterial cells was determined by plating samples that had been heated at $70^{\circ} \mathrm{C}$ for $10 \mathrm{~min}$ onto Nutrient Agar. Physiological groups of microorganisms present in the sediment samples were identified by inoculating them on selective agar or into liquid medium. The most probable number (MPN) method was used to determine the CFU/mL of ammonifying, nitrifying, denitrifying, and sulfate-reducing bacteria [35]. The number of amylolytic, proteolytic, lipolytic, ammonifying, nitrifying, denitrifying, and sulfate-reducing bacteria and actinomycetes was determined using specific media, as described previously [32]. Liquid cultures or plates were incubated at $26^{\circ} \mathrm{C}$ for three days (proteolytic, amylolytic, and ammonifying bacteria), seven days (actinomycetes, denitrifying, lipolytic, and sulfate-reducing bacteria), or 14 days (nitrifying bacteria). The number of bacteria was calculated per gram wet weight of sediment and per $1 \mathrm{~mL}$ of water.

\author{
Isolation and Identification \\ of Antibiotic-Resistant Bacteria
}

Antibiotic-resistant bacteria were isolated from water and bottom sediments by suspending the samples in saline and plating onto R2 Agar complete medium (Graso Biotech, Starogard Gdanski, Poland) supplemented with streptomycin, tetracycline, or erythromycin to a final concentration of $10 \mu \mathrm{g} / \mathrm{mL}$. R2A Agar is dedicated to the recovery and isolation of aerobic and facultative anaerobic heterotrophic bacteria. Only this group of bacteria can multiply in the body of animals and humans. In addition, this medium allows for the growth of slow-growing bacteria, which would be quickly suppressed by fastergrowing species on a richer culture medium. Also, the heterotrophic bacteria recovery method using R2A agar requires incubation temperatures below routine laboratory requirements, which further enhances the recovery of many stressed bacteria. The plates were incubated for 2448 hours at room temperature. Strains were stored at $4^{\circ} \mathrm{C}$ on agar plates supplemented with antibiotics and in LB with $10 \%$ glycerol at $-70^{\circ} \mathrm{C}$. All isolates were identified to genus level by sequencing the complete nucleotide sequence of the $16 \mathrm{~S}$ rRNA gene using colony PCR. Amplification reactions of $25 \mu \mathrm{L}$ contained one to four $\mu \mathrm{l}$ of the lysed cell samples; DreamTaq polymerase buffer with $1.5 \mathrm{mM} \mathrm{MgCl}_{2}, 0.2 \mathrm{mM}$ dNTP, $1 \mathrm{mM}$ of each primer 27F (AGAGTTTGATCCTGGCTCAG); and 1492R (GGTTACCTTGTTACGACTT) and 1U of DreamTaq polymerase (Fermentas) [36]. PCR was performed using a Mastercycler EP gradient S thermocycler (Eppendorf, Hamburg, Germany) under the following conditions: $5 \mathrm{~min}$ at $94^{\circ} \mathrm{C}$, followed by 20 cycles of $30 \mathrm{~s}$ at $94^{\circ} \mathrm{C}, 50$ $\mathrm{s}$ at $53^{\circ} \mathrm{C}$, and $1 \mathrm{~min} 20 \mathrm{~s}$ at $72^{\circ} \mathrm{C}$; and 15 cycles of $30 \mathrm{~s}$ at $94^{\circ} \mathrm{C}, 30 \mathrm{~s}$ at $46^{\circ} \mathrm{C}$, and $1 \mathrm{~min} 20 \mathrm{~s}$ at $72^{\circ} \mathrm{C}$; followed by one cycle of $10 \mathrm{~min}$ at $72^{\circ} \mathrm{C}$. PCR products were separated by $0.8 \%$ agarose gel electrophoresis and purified using a PCR Purification Kit (Qiagen, Hilden, Germany) or the Gel Out kit (DNA Gdansk II), according to the manufacturer's instructions. PCR amplicons were sequenced by Genomed (Warsaw, Poland) and sequence analysis was performed using the Clone program. Speciation was performed by BLAST (blast.ncbi.nlm.nih.gov/Blast.cgi) and comparison with the Ribosomal Database Project (rdp.cme.msu.edu). Genus-level identifications were performed using the following criteria: a bacterium was assigned to a particular genus when more than $95 \%$ identity was detected.

16S rRNA sequences were aligned using the builtin ClustalW (default parameters), and a phylogenetic tree was built using the maximum parsimony method with default parameters and 300 bootstrap replications with the MEGA6 software. Accession numbers for the reference strains are as follows: Arthrobacter sp. Rue61a - NC_018531; Bacillus cereus E33L - NC_006274; Bacillus subtilis subsp. subtilis str. 168 - NC_000964; Escherichia coli str. K-12 substr. W3110 - NC_007779; Flavobacterium psychrophilum JIP02/86 - NC_009613; Pedobacter saltans DSM 12145 - NC_015177; Pseudomonas fluorescens SBW25 - NC_012660; 
Pseudomonas putida NBRC 14164 - NC 021505; and Stenotrophomonas maltophilia D457 - NC_ 017671.

\section{Antibiotic Resistance Screening}

The susceptibility of bacterial isolates to tetracycline, streptomycin, and erythromycin at concentrations of $30 \mu \mathrm{g}, 10 \mu \mathrm{g}$, and $15 \mu \mathrm{g}$, respectively, was determined using the standard CLSI disk diffusion method (CLSI 2012). The plates were incubated from 24 to $48 \mathrm{~h}$ at room temperature. For the bacterial genera that have not been included in CLSI guidelines, lack of an inhibition zone around the disk (disc has a diameter $6 \mathrm{~mm}$ ) was selected as the breakpoint for the resistant profile.

\section{Determination of Multiple Antibiotic Resistance} (MAR) Index

The MAR index was calculated for each isolate based on the results of the disc diffusion method. The MAR index for a single isolate was calculated as the number of antibiotics to which the isolate is resistant divided by the total number of antibiotics against which the isolate was tested. In this situation, the total number of antibiotics was 3 , so the strain could reach a value of $0.3,0.7$ or 1 .

\section{Identification of Resistance Genes}

Tetracycline, streptomycin, and erythromycin resistance genes were identified by PCR amplification using primers specific for each gene as previously described [37] (Tables 1 to 3). Positive and negative controls were used in each run. Nucleotide sequences of reference-resistance genes were extracted from the NCBI (ncbi.nlm.nih.gov) and ARDB (arpcard.mcmaster.ca) databases to design specific PCR primers. The reference nucleotide sequences: AF321548 (Pseudomonas sp. PsR9), AJ862840 (Streptomyces griseus subsp. griseus), AY602212 (Enterococcus faecium), AY602406 (Salmonella enterica), and EF031554 (Salmonella enterica subsp. enterica) were used to design PCR primers for the amplification of the streptomycin-resistant genes $\operatorname{str}(\mathrm{A})$,

Table 1. Primers used to amplify tetracycline-resistant genes in PCR experiments.

\begin{tabular}{|c|c|c|c|c|}
\hline Gene & Forward primer $\left(5^{\prime}-3^{\prime}\right)$ & Reverse primer $\left(3^{`}-5^{`}\right)$ & $\begin{array}{l}\text { Taa } \\
\left({ }^{\circ} \mathrm{C}\right)\end{array}$ & $\begin{array}{l}\text { Fragment size } \\
\text { (bp) }\end{array}$ \\
\hline $\operatorname{tet}(\mathrm{A})$ & CGATCTGGTTCACTCGAA & CCACGTTGTTATAGAAGCC & 51 & 1000 \\
\hline $\operatorname{tet}(\mathrm{B})$ & GTTCGACAAAGATCGCAT & CCCTGTAAAGCACCTTGC & 51 & 1000 \\
\hline $\operatorname{tet}(\mathrm{C})$ & TCCATTCCGACAGCATCG & AACCCGTTCCATGTGCTC & 57 & 1000 \\
\hline $\operatorname{tet}(\mathrm{D})$ & ATAAACCCGCTGTCATCG & ACACCCTGTAGTTTTCCC & 51 & 1000 \\
\hline $\operatorname{tet}(\mathrm{E})$ & GGAAAGGCTAATGTTGCAG & ATCCATTCCACGTTTCGC & 57 & 1000 \\
\hline $\operatorname{tet}(\mathrm{G})$ & AGGTCGCTGGACACTATG & ACAATCCAAACCCAACCG & 57 & 1000 \\
\hline $\operatorname{tet}(\mathrm{H})$ & TATACTGCTGATCACCGT & CACCAGAGTACCTTGTAA & 51 & 1000 \\
\hline $\operatorname{tet}(\mathrm{J})$ & TGAGCGAAAACAGACTCG & CCATCCCAATATTCAACG & 51 & 1000 \\
\hline $\operatorname{tet}(\mathrm{M})$ & CAAACAGAAGGTAGAACTG & TTGTTCACAACCATAGCG & 51 & 1000 \\
\hline $\operatorname{tet}(\mathrm{O})$ & GTCAGGGAAACCGTTTAA & TACGATAGGGGAAAGCAG & 51 & 1000 \\
\hline $\operatorname{tet}(\mathrm{AP})$ & ACAGGAGTGGGATTTATT & CAATACСТCCAАСТСТАТ & 50 & 1000 \\
\hline $\operatorname{tet}(\mathrm{BP})$ & GGTGGAATAGAACCTGAT & ATACCATAGGTGTCACAT & 50 & 1000 \\
\hline $\operatorname{tet}(\mathrm{Q})$ & CAAGATGTCCTGTTTATGC & GAATCCCTTCAAAAACGG & 58 & 1000 \\
\hline $\operatorname{tet}(\mathrm{S})$ & AAGGACAAACTTTCTGACG & ССТTCCATAACTGCATTT & 51 & 1007 \\
\hline $\operatorname{tet}(\mathrm{T})$ & AATTGTGAAGGTAGGTCAGG & TCTTAACCCTTCCTTGTTGC & 55 & 1000 \\
\hline $\operatorname{tet}(\mathrm{W})$ & GGAGGAAAATACCGACATA & AATCTTACAGTCCGTTACG & 51 & 1000 \\
\hline $\operatorname{tet}(\mathrm{X})$ & GACCGAGAGGCAAGAATT & GAAACGTAAAGTCGGGTT & 53 & 1000 \\
\hline $\operatorname{tet}(\mathrm{Y})$ & ACCGGCAGAGCAAACAGC & AACCCAACCATCCCACTG & 57 & 1000 \\
\hline $\operatorname{tet}(\mathrm{Z})$ & TACCCTTCTCGACCAGGT & ATTCGTTCGGGTGAGTGC & 57 & 1000 \\
\hline $\operatorname{tet}(30)$ & GGACATCTTGGTCGAGGTGA & GGTGGAAAAGAACACTGCGG & 51 & 1000 \\
\hline $\operatorname{tet}(32)$ & AACCGAAGCATACCGCTC & CTCTTTCATAGCCACGCC & 60 & 1000 \\
\hline $\operatorname{tet}(34)$ & TTCATTATCACTTGGGACGC & GCTTGCGATTAATTGGTTCC & 65 & 445 \\
\hline $\operatorname{tet}(36)$ & ATCCGTTGAAGGCAAGGA & ACCCGATTCACAGGCTTT & 60 & 1000 \\
\hline
\end{tabular}


Table 2. Primers used to amplify erythromycin-resistant genes in PCR experiments.

\begin{tabular}{|c|c|c|c|c|}
\hline Gene & Forward primer $\left(5^{`}-3^{\prime}\right)$ & Reverse primer $\left(3^{\prime}-5^{\prime}\right)$ & $\begin{array}{l}\text { Taa } \\
\left({ }^{\circ} \mathrm{C}\right)\end{array}$ & $\begin{array}{c}\text { Fragment } \\
\text { size (bp) }\end{array}$ \\
\hline $\operatorname{erm}(\mathrm{A})$ & GAAAAACCCTAAAGACACGCAAAA & AGTGACATTTGCATGCTTCAAAG & 58 & 658 \\
\hline $\operatorname{erm}(\mathrm{B})$ & AAAAATATAAAATATTCTCA & TAGACAATACTTGCTCATAAGTAAC & 49 & 694 \\
\hline $\operatorname{erm}(\mathrm{C})$ & TATTAAATAATTTATAGCTATTGAAAA & TGAACATGATAATATCTTTGAAAT & 50 & 644 \\
\hline $\operatorname{erm}(\mathrm{D})$ & GCTTTGACAACTGTGCTAAGTCAAAA & GGCCATTTGTGATGCATTACATA & 58 & 662 \\
\hline $\operatorname{erm}(\mathrm{E})$ & GCAGCACCCCAACCAGAA & GGTACTTGCGCAGAAGCGA & 58 & 662 \\
\hline $\operatorname{erm}(\mathrm{F})$ & TCGTTTTACGGGTCAGCACTT & AACTTCCAGCATTTCCAAAAAACA & 55 & 751 \\
\hline $\operatorname{erm}(\mathrm{G})$ & TCACATAGAAAAAATAATGAATTGCATAAG & CGATACAAATTGTTCGAAACTAATATTGT & 55 & 652 \\
\hline $\operatorname{erm}(\mathrm{Q})$ & AAGTTATTGGGTTACAGCTA & CACCTCCTAATTTAAATCTACTA & 54 & 623 \\
\hline $\operatorname{erm}(\mathrm{V})$ & CGCCGGACAGCTCGC & TCCCCCACCAGGACGTC & 60 & 669 \\
\hline $\operatorname{erm}(\mathrm{X})$ & CGTCACGAGCATGGCCA & CGAGCGCAACCATGATTATGT & 58 & 671 \\
\hline$m s r(\mathrm{~A})$ & GCAACGTATTAACGGAGTGC & GTCTTGATGATATTCTTCCGCAGG & 53 & 628 \\
\hline$m s r(\mathrm{~B})$ & GAGTGCGATGGAATTCAGGC & CGAACTAACGGAAGAACAGG & 52 & 956 \\
\hline $\operatorname{srm}(\mathrm{B})$ & CCTGGTTATTCTCAGCAACG & ACCTTCGATCACTCTCGGTT & 52 & 826 \\
\hline $\operatorname{vg} a(\mathrm{~A})$ & GTAGGCCGTAATGGAGCTGG & CGTCTACTCTTAGCCATGCC & 55 & 841 \\
\hline ole(B) & GCGAACAGCACACCATCCAC & GCCTCTTCGAGGTCTTCCAC & 56 & 912 \\
\hline
\end{tabular}

$\operatorname{str}(\mathrm{B}), \operatorname{aad}(\mathrm{K}), \operatorname{aad}(\mathrm{A})$, and $a a c$, respectively. Escherichia coli strains containing the $\operatorname{aad}(\mathrm{A})$ gene and the RSF1010 plasmid $\operatorname{str}(\mathrm{A})$ and $\operatorname{str}(\mathrm{B})$ genes were used as positive controls (AJ238350 and AF027768, respectively). E. coli DH5 $\alpha$ was used as a negative control. PCR was performed under the following conditions: $5 \mathrm{~min}$ at $94^{\circ} \mathrm{C}$, followed by 35 cycles of $30 \mathrm{~s}$ at $94^{\circ} \mathrm{C}, 30 \mathrm{~s}$ at 49 or $60^{\circ} \mathrm{C}$ and 1 min at $72^{\circ} \mathrm{C}$, and finally one cycle of $7 \mathrm{~min}$ at $72^{\circ} \mathrm{C}$. PCR products were separated on $0.8 \%$ or $1 \%$ agarose gels. PCR amplicons were also sequenced by Genomed (Poland). Identification was performed using BLAST (blast.ncbi. nlm.nih.gov/Blast.cgi) and the ARDB database.

\section{Statistical Analysis}

A statistical analysis was carried out using Statistica version 6 software (StatSoft, Inc Tulsa, Oklahoma). Data generated on the distribution frequency of a variety of genera and antibiotic resistance genes were analyzed using the Chi-square test to determine whether there were significant differences $(\mathrm{p}<0.05)$ between water and sediment.

\section{Results}

Characterization of the Total Pond Microbial Population

Water and bottom sediments of the ponds studied were characterized in terms of microbial diversity (Table 4). The total number of heterotrophic and prototrophic bacteria was higher in sediments cultured on R2 Agar solid media $\left(4.69 \times 10^{6} \mathrm{CFU} / \mathrm{g}\right.$ in sediments and $3.73 \times 10^{4}$

Table 3. Primers used to amplify streptomycin-resistant genes in PCR experiments.

\begin{tabular}{|c|c|c|c|c|}
\hline Gene & Forward primer $\left(5^{\prime}{ }^{\prime}{ }^{\prime}{ }^{\prime}\right)$ & Reverse primer $\left(3^{\prime}-5^{\prime}\right)$ & $\begin{array}{c}\text { Taa } \\
\left({ }^{\circ} \mathrm{C}\right)\end{array}$ & $\begin{array}{c}\text { Fragment } \\
\text { size }(\mathrm{bp})\end{array}$ \\
\hline $\operatorname{str}(\mathrm{A})$ & GAGAGCGTGACCGCCTCATT & TCTGCTTCATCTGGCGCTGC & 57 & 862 \\
\hline $\operatorname{str}(B)$ & GCTCGGTCGTGAGAACAATC & AGAATGCGTCCGCCATCTGT & 54 & 859 \\
\hline aad $(\mathrm{K})$ & CCTCCTGACAACTTCCAAGA & GCAAGACCTTCTGATACAGC & 52 & 891 \\
\hline aadA2 & GCGCCATCTGGAATCAACGT & TGCCGGTTATTGCGCTGTAC & 54 & 912 \\
\hline aac $\left(2^{\prime}\right)-I$ & ATCTGGCGGACGGCGAAGAA & GCGAGGTATCGGAAGCCATT & 53 & 856 \\
\hline aac $\left(6^{\prime}\right)-I$ & CATGACCTTGCGATGCTCTA & GCTCGAATGCCTGGCGTCTT & 58 & 490 \\
\hline aac(3)-I & TTACGCAGCAGCAACGATGT & GTTGGCCTCATGCTTGAGGA & 58 & 402 \\
\hline
\end{tabular}


Table 4. Number of microorganisms in the studied ponds.

\begin{tabular}{|c|c|c|}
\hline Group of bacteria & $\begin{array}{c}\text { Number of bac- } \\
\text { teria } \\
\text { (number of cells/g } \\
\text { wet weight of } \\
\text { sediment) }\end{array}$ & $\begin{array}{c}\text { Number of } \\
\text { bacteria } \\
\text { (number of } \\
\text { cells in } 1 \mathrm{ml} \\
\text { of water) }\end{array}$ \\
\hline Total (broth) & $4.69 \times 10^{6}$ & $3.73 \times 10^{4}$ \\
\hline Total (R2Agar/M9) & $3.62 \times 10^{5}$ & $1.53 \times 10^{4}$ \\
\hline Spore-forming & $5.52 \times 10^{4}$ & $1.25 \times 10^{3}$ \\
\hline Amylolytic & $6.3 \times 10^{4}$ & $1.2 \times 10^{3}$ \\
\hline Proteolytic & $5.29 \times 10^{4}$ & $8.83 \times 10^{2}$ \\
\hline Lipolytic & $6.1 \times 10^{5}$ & $1.83 \times 10^{2}$ \\
\hline Ammonifying & $7 \times 10^{4}$ & $3.06 \times 10^{5}$ \\
\hline Nitrifying & $2.48 \times 10^{3}$ & $5.48 \times 10^{3}$ \\
\hline Denitrifying & $1.65 \times 10^{3}$ & 4.5 \\
\hline Sulfate reducing Bacteria & $5.5 \times 10^{3}$ & $2 \times 10^{1}$ \\
\hline Actinomycetes & $6.05 \times 10^{3}$ & $6.64 \times 10^{2}$ \\
\hline \multicolumn{2}{|l}{} \\
\hline
\end{tabular}

$\mathrm{CFU} / \mathrm{mL}$ in water), and M9 mineral solid media (3.62 x $10^{5} \mathrm{CFU} / \mathrm{g}$ in sediments and $1.53 \times 10^{4} \mathrm{CFU} / \mathrm{mL}$ in water) compared to water samples. Spore-forming bacteria were also found in both environments, with the greater contribution of sediment isolates $\left(5.52 \times 10^{4}\right)$. To better characterize the microbiome of ponds we also determined the number of actinomycetous, amylolytic, proteolytic, lipolytic, denitrifying, and sulfate-reducing bacteria. All of these groups were identified in both environments, but again they were more abundant in bottom sediments $\left(6.05 \times 10^{3}, 6.3 \times 10^{4}, 5.29 \times 10^{4}, 6.1 \times 10^{5}, 1.65 \times 10^{3}\right.$, and $5.5 \times 10^{3} \mathrm{CFU} / \mathrm{g}$, respectively). Lastly, we also found ammonifying and nitrifying bacteria, but these isolates were more common in water $\left(3.06 \times 10^{5}\right.$ and $5.48 \times 10^{3}$ $\mathrm{CFU} / \mathrm{mL}$, respectively).

The next stage of the experiment was to determine the number of bacteria with the ability to grow on an agar medium (AO) with the antibiotics tested: streptomycin, erythromycin, or tetracycline. Water or sediments sampled from the fish ponds were directly inoculated on these media. Bacterial counts capable of growing on a medium with tetracycline, streptomycin, and erythromycin were $2.78 \times 10^{3}, 7.0 \times 10^{2}$, and $2.1 \times 10^{2} \mathrm{CFU} / \mathrm{mL}$ for water, and $5.02 \times 10^{5}, 8.52 \times 10^{5}$, and $2.48 \times 10^{4} \mathrm{CFU} / \mathrm{g}$ for sediments, respectively.

\section{Identification and Phenotypic Resistance of Bacterial Isolates}

The identified bacteria belonged to a variety of genera, including Arthrobacter, Bacillus, Chryseobacterium, Flavobacterium, Microbacterium, Pseudomonas, and Stenotrophomonas, and single cases of Janibacter, Myroides, Pedobacter, Paenibacillus, Rhodococcus, and Sphingobacterium (Tables 5, 6). The phylogenetic relationships of the strains from sediment and water are shown in Fig. 1 (respectively a and b). The most common isolates in sediment $(100 \%, n=24)$ were Pseudomonas spp. and Bacillus spp. $(29.2 \%, n=7$ and $25 \%, n=6$, respectively). The aquatic environment $(100 \%, n=34)$ was characterized by greater diversity of bacterial genera; the most frequently isolated were Stenotrophomonas spp. but, similar to sediments, Pseudomonas spp. also formed a large group of naturally occurring bacteria $(29.4 \%$, $n=10$ and $20.6 \%, n=7$, respectively). There were significant differences in the prevalence of Pseudomonas spp., Bacillus spp., and Stenotrophomonas spp. isolates between the studied environments.

Pure cultures of bacterial isolates were tested for susceptibility to tetracycline, streptomycin, and erythromycin using the disk diffusion method (data not shown). A preliminary screening of strains was carried out to discard repeated isolates.

Twenty-four and 34 non-susceptible isolates were selected for the next step from the bottom sediments and water, respectively. The distribution of strains able to grow on streptomycin, erythromycin, and tetracycline was different in each environment. A higher percentage of water isolates (more than 90\%, streptomycin $=31$; tetracycline $=32$; erythromycin $=32$ ) were able to grow on each of the three antibiotics as compared to the strains from bottom sediments. Growth on streptomycin was reported to be the most frequent in the latter isolates $(87.5 \%, n=21)$, while erythromycin and tetracycline resistance was reported at a significantly lower level: $62.5 \%, n=15$ and $42.0 \%, n=10$, respectively. Phenotypic resistance of the isolates, as determined by the disc diffusion method is listed in Table 5 (sediment strains) and Table 6 (water strains) in the form of a MAR index. Most of the tested isolates demonstrated phenotypic resistance to one, two, or three antibiotics. MAR indices ranging from 0 to 1 have been identified for both the environments (Tables 5 and 6). The isolates carrying resistance to two antibiotics (MAR $=0.7$ ) were observed most frequently in the sediments $(37.5 \%, n=9)$, even though resistance to one $(\mathrm{MAR}=0.3)$ and three $(\mathrm{MAR}=1)$ antibiotics have been observed in similar proportions (both 29.2\%, $n=7$ ). Among water strains resistance to all three antibiotics and to one antibiotic was at a similar level $(38.2 \%, n=13$ and $32.4 \%, n=11$ respectively), while a smaller percentage showed resistance to two antimicrobials $(17.6 \%, n=6)$. There were no significant differences in the prevalence of the phenotypically resistant isolates between the studied environments.

An analysis of different resistance profiles between the isolated bacterial genera revealed that all identified Pseudomonas and Stenotrophomonas strains in both environments were phenotypically resistant to erythromycin. The resistance to streptomycin and tetracycline was significantly lower in aquatic Pseudomonas isolates (29\%, $n=2$ and 14\%, $n=1$ respectively) than in sedimentary strains of this genus $(57 \%$, $n=4$ and $43 \%, n=3)$. Stenotrophomonas strains that were isolated mainly from the water were also characterized by a very high level of resistance to tetracycline $(90 \%$, $n=9)$ and high resistance to streptomycin $(60 \%$, 
Table 5. Characteristics of antibiotic-resistant bacteria isolated from the bottom sediments of fish ponds.

\begin{tabular}{|c|c|c|c|c|c|c|}
\hline No. & $\begin{array}{c}\text { Bacterial isolates } \\
\text { (Species/Identities) }\end{array}$ & $\begin{array}{l}\text { Susceptibility } \\
\text { profile }\end{array}$ & MAR index & $\begin{array}{l}\text { Tetracycline- } \\
\text { resistant genes }\end{array}$ & $\begin{array}{l}\text { Streptomycin- } \\
\text { resistant genes }\end{array}$ & $\begin{array}{l}\text { Erythromycin- } \\
\text { resistant genes }\end{array}$ \\
\hline $1 \mathrm{~S}$ & $\begin{array}{l}\text { Flavobacterium sp. } \\
\text { (F. hercynium/98\%) }\end{array}$ & STR & 0.7 & - & - & - \\
\hline $2 \mathrm{~S}$ & $\begin{array}{l}\text { Flavobacterium sp. } \\
\text { (F. hercynium/98\%) }\end{array}$ & STR, TET, ERY & 0.3 & $\operatorname{tet}(\mathrm{H}), \operatorname{tet}(\mathrm{X})$ & $\operatorname{aac}\left(6^{\prime}\right)-I$ & $\operatorname{erm}(\mathrm{G}), \operatorname{msr}(\mathrm{A})$ \\
\hline $3 \mathrm{~S}$ & $\begin{array}{l}\text { Pedobacter sp. } \\
\text { (P. steynii/99\%) }\end{array}$ & STR, ERY & 1 & - & - & $\begin{array}{l}\operatorname{erm}(\mathrm{F}), \operatorname{msr}(\mathrm{B}), \\
\operatorname{srm}(\mathrm{B}), \operatorname{vga}(\mathrm{A})\end{array}$ \\
\hline $4 \mathrm{~S}$ & $\begin{array}{l}\text { Stenotrophomonas sp. } \\
\text { (S. rhizophila/99\%) }\end{array}$ & STR, TET, ERY & 0.3 & - & - & - \\
\hline $5 \mathrm{~S}$ & $\begin{array}{l}\text { Flavobacterium sp. } \\
\text { (F. hercynium/98\%) }\end{array}$ & STR, TET, ERY & 0.7 & $\begin{array}{c}\text { tet }(\mathrm{H}), \operatorname{tet}(\mathrm{BP}), \\
\operatorname{tet}(\mathrm{X})\end{array}$ & $\operatorname{aac}\left(6^{\prime}\right)-I$ & $\begin{array}{c}\operatorname{erm}(\mathrm{G}), \operatorname{msr}(\mathrm{A}), \\
\operatorname{srm}(\mathrm{B})\end{array}$ \\
\hline $6 \mathrm{~S}$ & $\begin{array}{c}\text { Paenibacillus sp. } \\
\text { (P. amylolyticus/98\%) }\end{array}$ & STR & 1 & - & - & - \\
\hline $7 \mathrm{~S}$ & $\begin{array}{l}\text { Pseudomonas sp. } \\
\text { (P. mandelii/98\%) }\end{array}$ & STR, TET, ERY & 0.7 & & $\operatorname{aad}(\mathrm{K})$ & - \\
\hline $8 \mathrm{~S}$ & $\begin{array}{c}\text { Bacillus sp. } \\
\text { (B. mycoides } / 99 \%)\end{array}$ & STR & 0.3 & - & - & - \\
\hline $9 \mathrm{~S}$ & $\begin{array}{c}\text { Pseudomonas sp. } \\
\text { (P. fluorescens/99\%) }\end{array}$ & STR, TET, ERY & 0.3 & $\begin{array}{l}\operatorname{tet}(\mathrm{E}), \operatorname{tet}(\mathrm{G}), \\
\operatorname{tet}(\mathrm{H}), \operatorname{tet}(\mathrm{M}), \\
\operatorname{tet}(\mathrm{BP}), \operatorname{tet}(\mathrm{T}), \\
\operatorname{tet}(\mathrm{Z})\end{array}$ & $\begin{array}{c}\operatorname{str}(\mathrm{A}), \operatorname{str}(\mathrm{B}), \\
\operatorname{aadA2}, \operatorname{aac}(6>)-I\end{array}$ & $\begin{array}{c}\operatorname{erm}(\mathrm{A}), \operatorname{erm}(X), \\
m s r(\mathrm{~A}), \operatorname{srm}(\mathrm{B}), \\
\operatorname{vga}(\mathrm{A})\end{array}$ \\
\hline $10 \mathrm{~S}$ & $\begin{array}{c}\text { Bacillus } \mathrm{sp.} \\
\text { (B. clausii/98\%) } \\
\end{array}$ & STR, ERY & 0.7 & - & - & $\operatorname{erm}(\mathrm{E})$ \\
\hline $11 \mathrm{~S}$ & $\begin{array}{c}\text { Paenibacillus sp. } \\
\text { (P. pabuli/98\%) }\end{array}$ & STR & 1 & - & - & - \\
\hline $12 \mathrm{~S}$ & $\begin{array}{c}\text { Bacillus sp. } \\
\text { (B. cereus } / 98 \%)\end{array}$ & TET & 0.3 & $\operatorname{tet}(\mathrm{W}), \operatorname{tet}(\mathrm{Y})$ & - & - \\
\hline $13 \mathrm{~S}$ & $\begin{array}{c}\text { Pseudomonas sp. } \\
\text { (P. fluorescens } / 98 \%)\end{array}$ & STR, TET, ERY & 0.7 & $\begin{array}{l}\text { tet }(\mathrm{A}), \operatorname{tet}(\mathrm{M}) \\
\operatorname{tet}(\mathrm{X})\end{array}$ & $\operatorname{aac}\left(6^{\prime}\right)-I$ & $\begin{array}{l}\operatorname{erm}(\mathrm{A}), \operatorname{erm}(\mathrm{E}), \\
\operatorname{erm}(\mathrm{F}), \operatorname{erm}(\mathrm{Q}), \\
\operatorname{erm}(\mathrm{V}), \operatorname{srm}(\mathrm{B})\end{array}$ \\
\hline $14 \mathrm{~S}$ & $\begin{array}{c}\text { Pseudomonas sp. } \\
\text { (P. fluorescens } / 99 \%)\end{array}$ & TET, ERY & 1 & $\begin{array}{l}\operatorname{tet}(\mathrm{M}), \operatorname{tet}(32), \\
\operatorname{tet}(34), \operatorname{tet}(36)\end{array}$ & - & $\operatorname{erm}(\mathrm{F}), \operatorname{erm}(\mathrm{V})$ \\
\hline $15 \mathrm{~S}$ & Arthrobacter sp. & STR & 0.7 & - & - & - \\
\hline $16 \mathrm{~S}$ & $\begin{array}{l}\text { Pseudomonas sp. } \\
\text { (P. salomonii/98\%) }\end{array}$ & STR, ERY & 1 & - & - & $\operatorname{erm}(\mathrm{F}), \operatorname{erm}(\mathrm{V})$ \\
\hline $17 \mathrm{~S}$ & $\begin{array}{l}\text { Pseudomonas sp. } \\
\text { (P. mandelii/99\%) }\end{array}$ & STR, ERY & 0.7 & - & - & $\begin{array}{c}\operatorname{erm}(\mathrm{F}), \operatorname{erm}(\mathrm{V}), \\
\operatorname{vga}(\mathrm{A}), \operatorname{ole}(\mathrm{B})\end{array}$ \\
\hline $18 \mathrm{~S}$ & $\begin{array}{c}\text { Bacillus } \mathrm{sp.} \\
\text { (B. clausii/98\%) } \\
\end{array}$ & STR, ERY & 0.7 & - & - & ole(B) \\
\hline $19 \mathrm{~S}$ & Janibacter sp. & TET, ERY & 1 & $\operatorname{tet}(\mathrm{X})$ & - & - \\
\hline $20 \mathrm{~S}$ & $\begin{array}{l}\text { Pseudomonas sp. } \\
\text { ( P. fluorescens/98\%) }\end{array}$ & STR, TET, ERY & 0.3 & $\begin{array}{c}\operatorname{tet}(\mathrm{E}), \operatorname{tet}(\mathrm{G}), \\
\operatorname{tet}(\mathrm{H}), \operatorname{tet}(\mathrm{M}), \\
\operatorname{tet}(\mathrm{BP}), \operatorname{tet}(\mathrm{X}), \\
\operatorname{tet}(\mathrm{Y})\end{array}$ & $\operatorname{str}(\mathrm{A}), \operatorname{aac}\left(6_{>}\right)-I$ & $\begin{array}{c}\operatorname{erm}(\mathrm{F}), \operatorname{erm}(\mathrm{V}), \\
\operatorname{vga}(\mathrm{A}), \operatorname{msr}(\mathrm{B})\end{array}$ \\
\hline $21 \mathrm{~S}$ & $\begin{array}{c}\text { Bacillus sp. } \\
\text { (B. clausii/98\%) }\end{array}$ & STR, ERY & 0.7 & - & - & $\operatorname{erm}(\mathrm{V})$ \\
\hline $22 \mathrm{~S}$ & $\begin{array}{c}\text { Brevundimonas sp. } \\
\text { (B. bullata/99\%) }\end{array}$ & STR & 1 & - & - & - \\
\hline $23 \mathrm{~S}$ & $\begin{array}{c}\text { Arthrobacter } \mathrm{sp} . \\
\text { (A. kerguelensis/99\%) }\end{array}$ & STR & 0 & - & - & - \\
\hline $24 \mathrm{~S}$ & $\begin{array}{c}\text { Bacillus sp. } \\
\text { (B. subtilis/99\%) }\end{array}$ & STR & 0.3 & - & - & - \\
\hline
\end{tabular}

Footnotes: STR - streptomycin, TET - tetracycline, ERY - erythromycin. 
Table 6. Characteristics of antibiotic-resistant bacteria isolated from fish pond water.

\begin{tabular}{|c|c|c|c|c|c|c|}
\hline No. & $\begin{array}{l}\text { Bacterial isolates } \\
\text { (Species/Identities) }\end{array}$ & Susceptibility profile & $\begin{array}{l}\text { MAR } \\
\text { index }\end{array}$ & $\begin{array}{l}\text { Tetracycline- } \\
\text { resistant genes }\end{array}$ & $\begin{array}{l}\text { Streptomycin- } \\
\text { resistant genes }\end{array}$ & $\begin{array}{l}\text { Erythromycin- } \\
\text { resistant genes }\end{array}$ \\
\hline $1 \mathrm{~W}$ & $\begin{array}{l}\text { Pseudomonas sp. } \\
\text { (P. fluorescens/99\%) }\end{array}$ & STR, TET, ERY & 0.3 & $\operatorname{tet}(\mathrm{B})$ & $\operatorname{str}(\mathrm{A}), \operatorname{aac}\left(6^{\prime}\right)-I$ & $\operatorname{erm}(\mathrm{V}), \operatorname{erm}(\mathrm{X})$ \\
\hline $2 \mathrm{~W}$ & $\begin{array}{l}\text { Pseudomonas sp. } \\
\text { (P. baetica/98\%) }\end{array}$ & STR, TET, ERY & 0.3 & $\operatorname{tet}(\mathrm{C})$ & $\operatorname{str}(\mathrm{A})$ & - \\
\hline $5 \mathrm{~W}$ & $\begin{array}{l}\text { Pseudomonas } \mathrm{sp} . \\
\text { (P. simiae/99\%) }\end{array}$ & STR, TET & 0.3 & - & - & - \\
\hline $6 \mathrm{~W}$ & $\begin{array}{l}\text { Stenotrophomonas sp. } \\
\text { (S. maltophilia/99\%) }\end{array}$ & STR, TET, ERY & 0.3 & - & - & - \\
\hline $8 \mathrm{~W}$ & $\begin{array}{l}\text { Flavobacterium sp. } \\
(\text { F. oncorhynchi/98\%) }\end{array}$ & STR, TET, ERY & 0.3 & $\begin{array}{l}\operatorname{tet}(\mathrm{B}), \operatorname{tet}(\mathrm{O}) \\
\operatorname{tet}(\mathrm{T}), \operatorname{tet}(\mathrm{I}) \\
\operatorname{tet}(32)\end{array}$ & $\operatorname{str}(\mathrm{A}), \operatorname{aac}\left(6^{\prime}\right)-I$ & $\operatorname{erm}(\mathrm{F}), m s r(\mathrm{~A})$ \\
\hline $9 \mathrm{~W}$ & $\begin{array}{l}\text { Pseudomonas sp. } \\
\text { (P. poae/99\%) }\end{array}$ & STR, TET, ERY & 0.3 & $\operatorname{tet}(\mathrm{C}), \operatorname{tet}(\mathrm{T})$ & $\operatorname{str}(\mathrm{A}), \operatorname{str}(\mathrm{B})$ & $\operatorname{erm}(\mathrm{E}), \operatorname{erm}(\mathrm{V})$ \\
\hline $11 \mathrm{~W}$ & $\begin{array}{l}\text { Microbacterium } \mathrm{sp} . \\
(\text { M. oxydans/99\%) }\end{array}$ & TET, ERY & 0 & $\begin{array}{l}\operatorname{tet}(\mathrm{C}), \operatorname{tet}(\mathrm{D}) \\
\operatorname{tet}(\mathrm{I})\end{array}$ & $\operatorname{str}(\mathrm{B}), \operatorname{aac}\left(6^{\prime}\right)-I$ & - \\
\hline $12 \mathrm{~W}$ & $\begin{array}{c}\text { Arthrobacter } \mathrm{sp} . \\
\text { (A. arilaitensis } / 99 \%)\end{array}$ & STR, TET, ERY & 0.3 & $\operatorname{tet}(32)$ & - & $\operatorname{erm}(\mathrm{X})$ \\
\hline $13 \mathrm{~W}$ & $\begin{array}{l}\text { Microbacterium sp. } \\
\text { (M. oxydans } / 99 \%)\end{array}$ & STR, TET, ERY & 0 & - & $\operatorname{str}(\mathrm{B}), \operatorname{aac}\left(6^{\prime}\right)-I$ & - \\
\hline $14 \mathrm{~W}$ & Rhodococcus sp. & STR, TET, ERY & 0.3 & $\begin{array}{c}\operatorname{tet}(\mathrm{D}), \\
\operatorname{tet}(30), \operatorname{tet}(32)\end{array}$ & $\operatorname{str}(\mathrm{A}), \operatorname{str}(\mathrm{B})$ & $\operatorname{erm}(\mathrm{C}), \operatorname{erm}(\mathrm{V})$ \\
\hline $15 \mathrm{~W}$ & $\begin{array}{l}\text { Microbacterium } \mathrm{sp.} \\
(\text { M. oxydans } / 99 \%)\end{array}$ & TET, ERY & 0.7 & $\begin{array}{l}\operatorname{tet}(\mathrm{B}), \operatorname{tet}(\mathrm{C}), \\
\operatorname{tet}(\mathrm{D}), \operatorname{tet}(32)\end{array}$ & $\operatorname{str}(\mathrm{B}), \operatorname{aac}\left(6^{\prime}\right)-I$ & - \\
\hline $16 \mathrm{~W}$ & $\begin{array}{l}\text { Stenotrophomonas sp. } \\
\text { (S. rhizophila/99\%) }\end{array}$ & STR, TET, ERY & 0.7 & $\operatorname{tet}(\mathrm{D})$ & - & $m s r(\mathrm{~A})$ \\
\hline $17 \mathrm{~W}$ & $\begin{array}{l}\text { Microbacterium } \mathrm{sp} . \\
(\text { M. oxydans } / 99 \%)\end{array}$ & STR, TET, ERY & 1 & $\operatorname{tet}(\mathrm{B}), \operatorname{tet}(\mathrm{D})$ & $\operatorname{str}(\mathrm{B}), \operatorname{aac}\left(6^{\prime}\right)-I$ & - \\
\hline $19 \mathrm{~W}$ & $\begin{array}{c}\text { Chryseobacterium sp. } \\
\text { (Ch. rhizosphaerae/99\%) }\end{array}$ & STR, TET, ERY & 1 & $\operatorname{tet}(\mathrm{O})$ & - & - \\
\hline $20 \mathrm{~W}$ & $\begin{array}{l}\text { Stenotrophomonas sp. } \\
(\text { S. rhizophila/99\%) }\end{array}$ & STR, TET, ERY & 0.7 & $\operatorname{tet}(\mathrm{B}), \operatorname{tet}(\mathrm{X})$ & $\operatorname{str}(\mathrm{B})$ & - \\
\hline $21 \mathrm{~W}$ & $\begin{array}{l}\text { Pseudomonas sp. } \\
(\text { P. baetica/99\%) }\end{array}$ & STR, TET, ERY & 0.3 & $\operatorname{tet} D, \operatorname{tet}(\mathrm{M})$ & $\begin{array}{l}\operatorname{str}(\mathrm{A}), \operatorname{str}(\mathrm{B}) \\
\operatorname{aac}\left(6^{\prime}\right)-I\end{array}$ & $\operatorname{erm}(\mathrm{X})$ \\
\hline $22 \mathrm{~W}$ & $\begin{array}{l}\text { Stenotrophomonas sp. } \\
(\text { S. rhizophila/99\%) }\end{array}$ & STR, TET, ERY & 0.7 & $\begin{array}{l}\operatorname{tet}(\mathrm{D}), \operatorname{tet}(\mathrm{M}), \\
\operatorname{tet}(\mathrm{I}), \operatorname{tet}(32)\end{array}$ & $\operatorname{str}(\mathrm{B})$ & - \\
\hline $23 \mathrm{~W}$ & $\begin{array}{l}\text { Stenotrophomonas sp. } \\
\text { (S. maltophilia/99\%) }\end{array}$ & STR, TET, ERY & 1 & - & $\operatorname{str}(\mathrm{A})$ & - \\
\hline $24 \mathrm{~W}$ & $\begin{array}{l}\text { Stenotrophomonas sp. } \\
(\text { S. maltophilia/99\%) }\end{array}$ & STR, TET, ERY & 1 & - & - & - \\
\hline $25 \mathrm{~W}$ & $\begin{array}{c}\text { Stenotrophomonas sp. } \\
\text { (S. maltophilia/99\%) }\end{array}$ & STR, TET, ERY & 1 & $\operatorname{tet}(34)$ & - & - \\
\hline $26 \mathrm{~W}$ & $\begin{array}{l}\text { Chryseobacterium } \mathrm{sp} . \\
\text { (Ch. vrystaatense } / 97 \%)\end{array}$ & STR, TET, ERY & 1 & $\operatorname{tet}(\mathrm{S}), \operatorname{tet}(34)$ & - & $\operatorname{erm}(\mathrm{C}), \operatorname{erm}(\mathrm{V})$ \\
\hline $27 \mathrm{~W}$ & $\begin{array}{c}\text { Arthrobacter sp. } \\
\text { (A. nicotianae/98\%) }\end{array}$ & STR, TET, ERY & 1 & - & $\operatorname{aac}\left(6^{\prime}\right)-I$ & $\operatorname{erm}(\mathrm{C}), \operatorname{erm}(\mathrm{V})$ \\
\hline $28 \mathrm{~W}$ & Stenotrophomonas sp. & STR, TET, ERY & 1 & tet $(\mathrm{M})$ & $\operatorname{str} K, \operatorname{aac}\left(6^{\prime}\right)-I$ & $\operatorname{erm}(\mathrm{C}), \operatorname{erm}(\mathrm{X})$ \\
\hline $30 \mathrm{~W}$ & $\begin{array}{l}\text { Pedobacter } \mathrm{sp} . \\
\text { (P. steynii/99\%) }\end{array}$ & STR, TET, ERY & 0.7 & $\begin{array}{l}\text { tet }(\mathrm{M}), \operatorname{tet} W \\
\operatorname{tet}(\mathrm{X}), \operatorname{tet}(\mathrm{S}) \\
\operatorname{tet}(32)\end{array}$ & $\operatorname{str}(\mathrm{A})$ & $\begin{array}{c}\operatorname{erm}(\mathrm{E}), \operatorname{erm}(\mathrm{V}), \\
m \operatorname{mr}(\mathrm{A})\end{array}$ \\
\hline $31 \mathrm{~W}$ & $\begin{array}{l}\text { Arthrobacter } \mathrm{sp} . \\
(\text { A. ilicis/99\%) }\end{array}$ & STR, TET & 0 & $\begin{array}{c}\operatorname{tet}(\mathrm{M}), \operatorname{tet}(\mathrm{O}), \\
\operatorname{tet}(\mathrm{X})\end{array}$ & - & - \\
\hline
\end{tabular}


Table 6. Continued.

\begin{tabular}{|c|c|c|c|c|c|c|}
\hline $32 \mathrm{~W}$ & $\begin{array}{c}\text { Arthrobacter sp. } \\
\text { (A. nitroguajacolicus/99\%) }\end{array}$ & ERY & 0 & - & - & $\operatorname{erm}(\mathrm{V})$ \\
\hline $33 \mathrm{~W}$ & $\begin{array}{l}\text { Pseudomonas sp. } \\
\text { (P. putida/98\%) }\end{array}$ & STR, TET, ERY & 1 & $\begin{array}{l}\operatorname{tet}(\mathrm{A}), \operatorname{tet}(\mathrm{B}), \\
\operatorname{tet}(\mathrm{D}), \operatorname{tet}(\mathrm{T}), \\
\operatorname{tet}(\mathrm{S}), \operatorname{tet}(30), \\
\operatorname{tet}(32), \operatorname{tet}(34)\end{array}$ & $\begin{array}{l}\operatorname{str}(\mathrm{A}), \operatorname{str}(\mathrm{B}) \\
\operatorname{str}(\mathrm{K}), \operatorname{aac}\left(6^{\prime}\right)-I\end{array}$ & $\begin{array}{c}\operatorname{erm}(\mathrm{C} \operatorname{erm}(\mathrm{F}), \\
\operatorname{erm}(\mathrm{V}), \operatorname{erm}(\mathrm{X})\end{array}$ \\
\hline $35 \mathrm{~W}$ & $\begin{array}{c}\text { Sphingobacterium sp. } \\
\text { (S. kitahiroshimense/99\%) }\end{array}$ & STR, TET, ERY & 1 & $\begin{array}{l}\operatorname{tet}(\mathrm{C}), \operatorname{tet}(\mathrm{D}), \\
\operatorname{tet}(\mathrm{T}), \operatorname{tet}(30)\end{array}$ & $\begin{array}{l}\operatorname{str}(\mathrm{A}), \operatorname{str}(\mathrm{B}), \operatorname{str} \\
(\mathrm{K}), \operatorname{aac}\left(6^{\prime}\right)-I\end{array}$ & $\begin{array}{c}\operatorname{erm}(\mathrm{C}), \operatorname{erm}(\mathrm{V}), \\
\operatorname{erm}(\mathrm{X})\end{array}$ \\
\hline $36 \mathrm{~W}$ & $\begin{array}{l}\text { Stenotrophomonas sp. } \\
\text { (S. maltophilia/99\%) }\end{array}$ & STR, TET, ERY & 1 & $\operatorname{tet}(\mathrm{B}), \operatorname{tet}(\mathrm{C})$ & $\operatorname{str}(\mathrm{B})$ & - \\
\hline $37 \mathrm{~W}$ & $\begin{array}{l}\text { Microbacterium } \mathrm{sp} . \\
\text { (M. oxydans/99\%) }\end{array}$ & STR, ERY & 0.3 & - & $\operatorname{str}(\mathrm{B})$ & $\operatorname{erm}(\mathrm{C}), \operatorname{erm}(\mathrm{X})$ \\
\hline $38 \mathrm{~W}$ & $\begin{array}{c}\text { Pseudomonas } \mathrm{sp} . \\
\text { (P. plecoglossicida/98\%) }\end{array}$ & STR, TET, ERY & 0.7 & $\operatorname{tet}(\mathrm{S})$ & $\operatorname{str}(\mathrm{A})$ & $\operatorname{erm}(\mathrm{C}), m s r(\mathrm{~A})$ \\
\hline $39 \mathrm{~W}$ & $\begin{array}{l}\text { Chryseobacterium } \mathrm{sp} . \\
\text { (Ch. shigense/97\%) }\end{array}$ & STR, TET, ERY & 0.3 & $\operatorname{tet}(\mathrm{S})$ & $\operatorname{str}(\mathrm{K})$ & - \\
\hline $40 \mathrm{~W}$ & Myroides sp. & STR, TET, ERY & 1 & $\operatorname{tet}(\mathrm{B})$ & - & $\begin{array}{c}\operatorname{erm}(\mathrm{C}), \operatorname{erm}(\mathrm{E}), \\
\operatorname{erm}(\mathrm{V})\end{array}$ \\
\hline $44 \mathrm{~W}$ & $\begin{array}{l}\text { Stenotrophomonas sp. } \\
\text { (S. maltophilia/99\%) }\end{array}$ & STR, TET, ERY & 1 & $\operatorname{tet}(\mathrm{B}), \operatorname{tet}(32)$ & $\operatorname{aac}\left(6^{\prime}\right)-I$ & $m s r(\mathrm{~A})$ \\
\hline
\end{tabular}

Footnotes: STR - streptomycin, TET - tetracycline, ERY - erythromycin.

a)

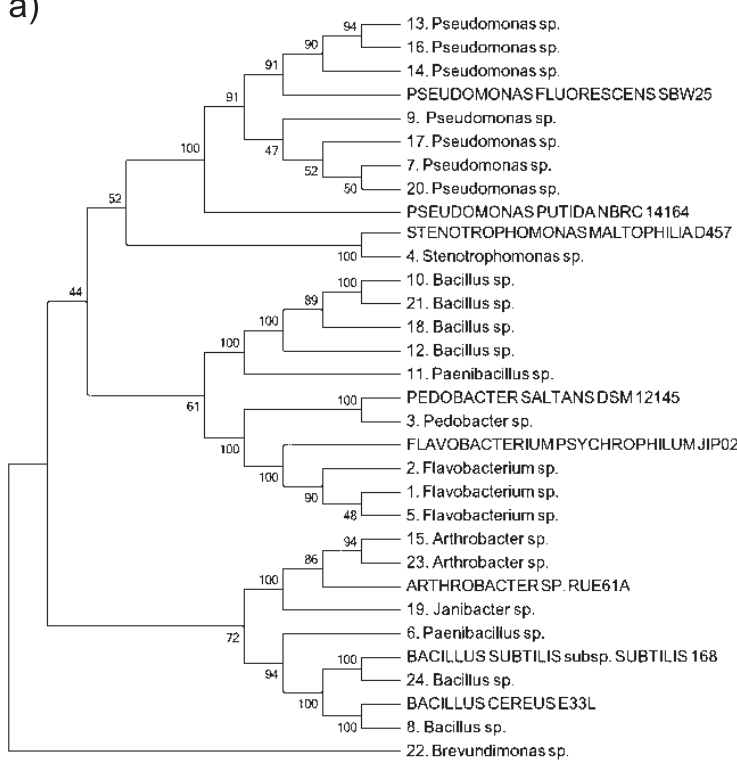

b)

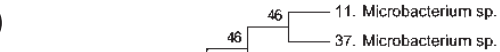

(11. Microbacterium sp. $51 \lcm{1} \quad$ 17. Microbacterium s 15. Microbacterium sp. (29-13. Microbacterium 12 Arthrobacter sp 28. 32 Arthrobacter sp. $100-31$ Anthroboderso. 50 ARTHROBACTER SP RUEE 1A. 14. Rhodococeus $\mathrm{sp}$ BACILLUS SUABTLLIS subsp. \$UBTTLIS 168 DACILLUS CEREUS E33 35. Sphingobacterium sp. 100 PEDOBACTER SALTANS DSM 12145 30. Pedobacter sp. $\$ 3$ 40. Myroides sp. ${ }_{100}$ LLAVOBACTERUMPSYCHROPHILUM 19. Chryseabacterium sp.

39. Chryseabacterium sp.

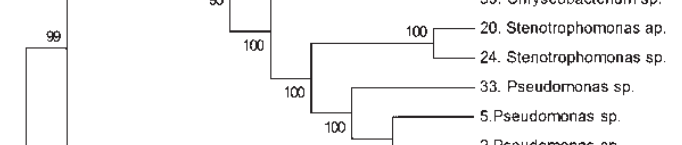
62 2 .Pseudomonas sp. 21. Pseudomanas $s$

PSEUDOMONAS FLUORESCENS SEW25

99 1.Pseudomronas sp.

100 PSEUDOMONAS PUTIDA NBRC 14164

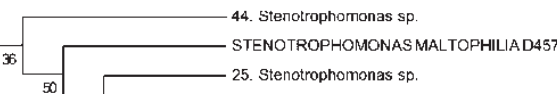

36. Stenotrophomionas sp

39 23. Stenotrophmonas

-16. Stentiotrophomonas sp

22. Stenotrophomonas sp.

Fig. 1. Dendrogram constructed on the basis of 16S rRNA gene sequencing for the isolates from sediment a), and water b). Maximum parsimony and maximum likelihood have been used to create them in order to assess tree stability. Bootstrap values were generated from 300 re-sampling. Reference strains are shown in capital letters. 


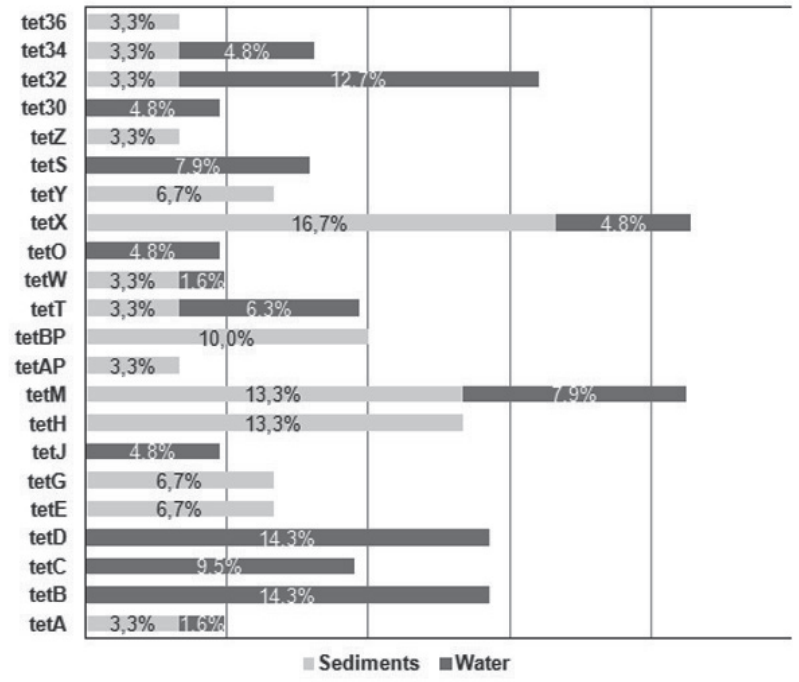

Fig. 2. Percentages of tetracycline-resistant genes among the water and sediments of aquaculture isolates.

$n=6)$. Among aquatic strains, Microbacterium spp. also showed high resistance to streptomycin $(60 \%, n=3)$ and Arthrobacter spp. to erythromycin $(50 \%, n=2)$. On the other hand, Bacillus strains isolated from the bottom sediment were highly resistant to tetracycline $(83 \%, n=5)$ and streptomycin $(50 \%, n=3)$.

\section{Detection of Antibiotic-Resistant Genes}

The key step of the study was the detection of ARG among phenotypically resistant strains. In the study, the following genes were selected for analysis: $\operatorname{tet}(\mathrm{A}), \operatorname{tet}(\mathrm{B})$, $\operatorname{tet}(\mathrm{C}), \operatorname{tet}(\mathrm{D}), \operatorname{tet}(\mathrm{E}), \operatorname{tet}(\mathrm{G}), \operatorname{tet}(\mathrm{H}), \operatorname{tet}(\mathrm{I}), \operatorname{tet}(\mathrm{M}), \operatorname{tet}(\mathrm{O})$, $t \operatorname{tet}(\mathrm{AP}), \operatorname{tet}(\mathrm{BR}), \operatorname{tet}(\mathrm{Q}), \operatorname{tet}(\mathrm{S}), \operatorname{tet}(\mathrm{T}), \operatorname{tet}(\mathrm{W}), \operatorname{tet}(\mathrm{X})$, $\operatorname{tet}(\mathrm{Y}), \operatorname{tet}(\mathrm{Z}), \operatorname{tet}(30), \operatorname{tet}(32), \operatorname{tet}(34)$, and $\operatorname{tet}(36)$ for tetracycline resistance; $\operatorname{str}(\mathrm{A}), \operatorname{str}(\mathrm{B}), \operatorname{aad}(\mathrm{K}), \operatorname{aad}(\mathrm{A} 2)$, and $\operatorname{aac}\left(6^{\prime}\right)-I$ for streptomycin resistance; and $\operatorname{erm}(\mathrm{A})$, $\operatorname{erm}(\mathrm{B}), \operatorname{erm}(\mathrm{C}), \operatorname{erm}(\mathrm{D}), \operatorname{erm}(\mathrm{E}), \operatorname{erm}(\mathrm{F}), \operatorname{erm}(\mathrm{G})$, $\operatorname{erm}(\mathrm{Q}), \operatorname{erm}(\mathrm{V}), \operatorname{erm}(\mathrm{X}), \operatorname{msr}(\mathrm{A}), \operatorname{msr}(\mathrm{B}), \operatorname{srm}(\mathrm{B})$, $\operatorname{vga}(\mathrm{A})$, and ole $(\mathrm{B})$ for erythromycin resistance. All the resistance genes were identified by PCR and sequencing

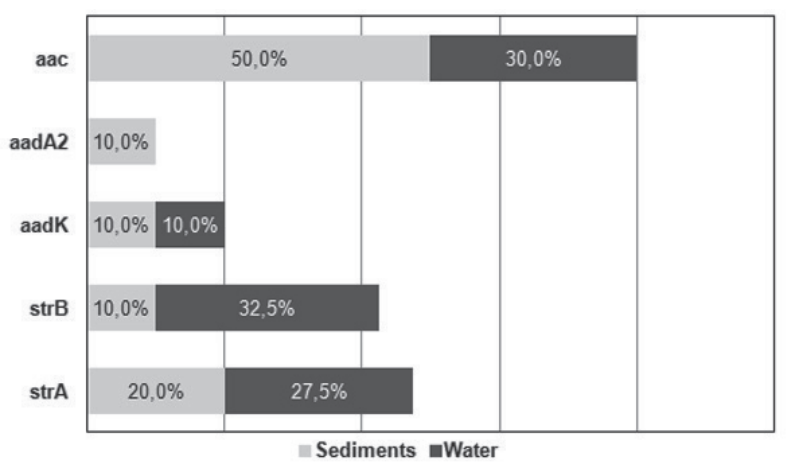

Fig. 3. Percentages of streptomycin-resistant genes among the water and sediments of aquaculture isolates.

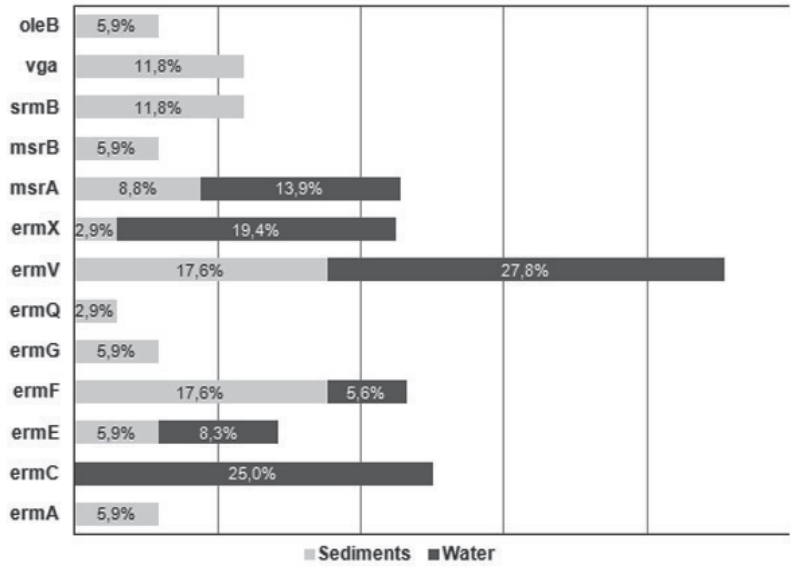

Fig. 4. Percentages of erythromycin-resistant genes among the water and sediments of aquaculture isolates.

(except for the $\operatorname{tet}(\mathrm{Q})$ gene that codes for tetracycline resistance and two genes, erm(B) and erm(D), responsible for erythromycin resistance). The identified ARGs are listed in Tables 5 and 6. Comparing these results with phenotypic resistance, it can be said that the detection of erythromycin resistance determinants was very high among sedimentary and aquatic isolates $(68.8 \%, \mathrm{n}=11$, and $64.3 \%, \mathrm{n}=18)$. Furthermore, streptomycin-resistant genes were found in $25.0 \%(n=6)$ and $67.6 \%(n=23)$, while tetracycline-resistant genes were detected in $33.3 \%$ $(\mathrm{n}=8)$ and $76.5 \%(\mathrm{n}=26)$ of sedimentary and aquatic isolates, respectively. The most frequent tetracyclineresistant genes in both the environments were tet $(\mathrm{M})$, tet $(\mathrm{X})$, and tet(32). Other genes that were common in both the habitats included $\operatorname{tet}(\mathrm{A}), \operatorname{tet}(\mathrm{T}), \operatorname{tet}(\mathrm{W})$, and tet(34) (Fig. 2). The most prevalent tet genes identified among sedimentary isolates were $\operatorname{tet}(\mathrm{X}), \operatorname{tet}(\mathrm{H}), \operatorname{tet}(\mathrm{M})$, and tet $(\mathrm{BP})$, while in aquatic isolates these were tet $(\mathrm{B})$, tet(D), tet(C), and tet(32). In both groups, the most common streptomycin-resistant gene was aac(6,)-I, but in aquatic isolates, $\operatorname{str}(\mathrm{A})$ and $\operatorname{str}(\mathrm{B})$ occurred with similar frequency (Fig. 3). The $\operatorname{aad}(\mathrm{A} 2)$ gene was found only in the isolates from sediments. Erythromycin-resistant genes detected among all the isolates were $\operatorname{msr}(\mathrm{A}), \operatorname{erm}(\mathrm{X})$, $\operatorname{erm}(\mathrm{V}), \operatorname{erm}(\mathrm{F})$, and erm(E) (Fig. 4). The following five genes were predominant in the aquatic strains: $\operatorname{msr}(\mathrm{A})$, $\operatorname{erm}(\mathrm{X}) \operatorname{erm}(\mathrm{V})$, and $\operatorname{erm}(\mathrm{C})$, while in sedimentary isolates these were: $\operatorname{erm}(\mathrm{V}), \operatorname{erm}(\mathrm{F}), \operatorname{vga}$, and $\operatorname{srm}(\mathrm{B})$. In addition, $\operatorname{erm}(\mathrm{C})$ was detected only in the water isolates. A study of different resistance genes between the isolated bacterial genera revealed some noteworthy correlations. $57 \%$ of sedimentary Pseudomonas isolates possessed tet $(\mathrm{M})$ genes and $71 \% \operatorname{erm}(\mathrm{F})$ and $71 \% \mathrm{erm}(\mathrm{V})$ genes. On the contrary, among aquatic isolates of Pseudomonas, $\operatorname{str}(\mathrm{A})$ genes were identified the most frequently (71\%). In the water isolates of Microbacterium, three genes were identified the most frequently: $\operatorname{str}(\mathrm{B})(100 \%)$, aac (80\%), and $\operatorname{tet}(\mathrm{D})(60 \%)$. 


\section{Discussion}

The studied fish ponds are located in a protected nature reserve in Poland. These ponds are used for ecological carp farming, thus the methods of feeding, fertilization, and preventive treatment of fish are in accordance with ecological principles. The environment investigated was characterized by higher total numbers of heterotrophic and prototrophic bacteria in sediments compared to water. This is probably due to the lower amount of easily assimilable organic compounds in the water environment necessary to support the growth of heterotrophic microbiota. Similar proportions have been previously reported in other studies [38, 39]. Soil, water, and sediments of the ponds are reservoirs of bacteria capable of utilizing the synthesis and degradation of both organic and inorganic compounds. There are groups of bacteria in bottom sediments of ponds and lakes involved in the metabolism of carbon, nitrogen, sulfur, and phosphorus [18]. These include nitrifying bacteria, denitrifying, amylolytic, cellulolytic, ammonifying, proteolytic ureolytic, sulfatereducing bacteria or methanogenic archaea. It should be emphasized that heterotrophic bacteria play an important role in the biodegradation of organic matter in aquatic environments, and the structure of microbial communities affects the stability of trophic status [4041]. The bacteria identified in our study belong to various genera with the predominance of Gram-negative bacteria such as Pseudomonas, Stenotrophomonas, and Flavobacterium. All these bacteria are typical for soil and water environments [42-43]. Because there is no known similar research in such an environment, but in which antibiotics had been used, it is difficult to comment on the obtained results. However, literature data indicate that the presence of antibacterial compounds strongly disturb the microbiome composition [41].

The analysis of growth on media containing antibiotics has shown that only $2 \%, 11 \%$, and $0.5 \%$ of the cultivable microbes from pond sediments showed the ability to grow in the presence of streptomycin, tetracycline, or erythromycin, respectively. The significantly greater percentage of strains non-susceptible to tetracycline may be due to the fact that the genes encoding tetracycline resistance are frequent in aquacultures [44]. In addition, literature data indicate that tetracycline-resistant genes persist at aquaculture farms in the absence of selection pressure [45]. As an example, the presence of tet(A), tet(B), tet $(\mathrm{D}), \operatorname{tet}(\mathrm{E}), \operatorname{tet}(\mathrm{G}), \operatorname{tet}(\mathrm{M}), \operatorname{tet}(\mathrm{O}), \operatorname{tet}(\mathrm{Q}), \operatorname{tet}(\mathrm{S})$, and tet $(\mathrm{W})$ genes in medicated and non-medicated feed samples and water samples from fish farms in the United States have been detected [46]. The proportions of resistance in aquatic isolates were identical to those obtained for sediment isolates, with the exception of strains carrying streptomycin resistance $(7.5 \%)$. Comparable results were obtained in fish farms from Pakistan and Tanzania with no recorded history of antibiotic use [47]. A study by Chelossi et al. [38], conducted using sediment samples from fish ponds, showed that the number of microorganisms capable of growth on media containing antibiotics is considerably higher. These authors demonstrated that approx. 77\%, $23.1 \%$, and $15.4 \%$ of the microorganisms had the ability to grow on a medium containing streptomycin, tetracycline, or erythromycin, respectively. Research carried out in aquacultures in Australia [48] showed that approx. 25\% of the strains were not susceptible to tetracycline, and even as many as approx. $47 \%$ were resistant to erythromycin.

$\mathrm{Su}$ et al. studied the level of antibiotic resistance in fish farms in southern China. The results revealed relatively high frequencies of antibiotic resistance, e.g., $52 \%$ of isolates were resistant to tetracycline. Out of 203 Enterobacteriaceae isolates, $98.5 \%$ were resistant to one or more antibiotics tested [49]. Similar results were obtained by Shah et al. in marine bacteria and the Chilean salmon aquaculture. Resistance to one or more antimicrobials was present in $81 \%$ of the isolates, regardless of the isolation site, and resistance to tetracycline was the most prevalent [47]. Hence in fish ponds, where antibiotics are used as feed additives, the number of strains non-susceptible to antibiotics is many times greater, which confirms the role of antibiotic pressure in the selection of such strains [6].

All the tested isolates demonstrated resistance to one, two, or three antibiotics. Generally, despite the small number of strains that were able to grow on media with antibiotics, bacterial strains derived from water showed a greater percentage of phenotypically resistant isolates to each of the three antibiotics compared with strains from bottom sediments. Sedimentary bacteria demonstrated most frequently resistance to streptomycin, while resistance to erythromycin and tetracycline was observed at a significantly lower level. MAR index values were relatively high and could indicate antibiotic contamination of the aquaculture facilities concerned. Given the proximity of Raszyn ponds to agricultural land and residential areas could also lead to co-pollutants. It is known that subinhibitory antimicrobial concentrations enhancing the selection for ARG $[25,28]$ can be sufficient selective factors of ARG [45, 50-51]. The persistence of ARGs in aquatic environmental bacteria is also possible even in the absence of sufficient selection pressure [27]. This is likely related to the location of many genes on mobile genetic elements such as plasmids, which in addition to resistance genes may encode other genes whose products are necessary for bacteria to survive in specific environments $[6,52-53]$. However, it seems that in the case of the studied environment the presence of so-called 'Natural (intrinsic) resistance' is essential [29]. Some of the isolated bacteria belonging to Pseudomonas spp., Stenorophomonas spp., Flavobacterium spp., and Bacillus spp., displayed a high level of intrinsic resistance to a variety of classes of antibiotics, including quinolones, $\beta$-lactams, tetracycline, and aminoglycosides [33, 54-56].

The resistance mechanism against tetracycline, streptomycin, and erythromycin has been explained in only $50 \%$ of the resistant isolates. This may indicate the existence of non-specific mechanisms of resistance in these strains, associated with the presence of mutations in genes encoding efflux pumps [28]. Generally, the percentage of detection of resistance genes among non- 
susceptible aquatic bacteria in antibiotic testing is higher, as compared with sedimentary bacteria. The profiles of the detected resistance genes are different in each of the environments tested. In both of them, the dominant mechanisms of tetracycline and erythromycin resistance are: efflux pumps, ribosomal protection, or enzymatic modification of rRNA [45, 57-58]. The latter is dominant in the streptomycin-resistant aquatic isolates, while enzymatic inactivation of the antibiotic is the most common in sedimentary isolates $[53,59]$. Resistance genes detected are typical for aquatic and soil environments [32, 60-62]. In our study, we observed a correlation between Pseudomonas and Microbacterium isolates and some identified genes. Both of these bacterial genera have been identified as opportunistic human pathogens. Moreover, the prevalence of erm genes among Pseudomonas isolates confirms the natural resistance to erythromycin in this genus. Generally, it can be concluded that the genes detected in the studied resistant bacteria are widespread among different ecological environments, this being undoubtedly associated with the localization of some of the ARG on mobile genetic elements such as plasmids and transposons.

\section{Conclusions}

Our results indicate that despite the lack of antibiotic use in the studied fish farms, antibiotic resistance genes were present in the bacterial isolates, and some of them belong to intrinsic genes. However, the level of antibiotic resistance was very low compared to aquacultures in which antibiotics are used. On the other hand, the occurrence of genes determining antibiotic resistance (which may spread in the case of antibiotic pressure, i.e., the use of these chemotherapeutics in a given environment) can pose a real and serious threat to human and animal health. Therefore, it seems important to develop different alternative strategies that could be used in the aquaculture industry to maximize the successful protection of animals and prevent the development of antibiotic resistance.

\section{Acknowledgements}

The authors' research was financed by a grant from the National Center of Science, Poland (741/N-COST/2010/0). The research was conducted as part of European Cooperation in the field of Scientific and Technical (COST) Research Action TD0803 "Detecting evolutionary hot spots of antibiotic resistance in Europe (DARE)" (200913).

\section{References}

1. BOSTOCK J., MCANDREW B., RICHARDS R., JAUNCEY K., TELFER T., LORENZEN K., LITTLE D., ROSS L., HANDISYDE N., GATWARD I., CORNER R.
Aquaculture: global status and trends. Philos Trans R Soc Lond B Biol Sci. 365, 2897, 2010.

2. KÜMMERER K. Antibiotics in the aquatic environment - a review - part I. Chemosphere. 75, 417, 2009.

3. KÜMMERER K. Antibiotics in the aquatic environment - a review - part II. Chemosphere. 75, 435, 2009.

4. SERRANO P.H. Responsible use of antibiotics in aquaculture. Food \& Agriculture Org. 2005.

5. ZHANG X.-X., ZHANG T., FANG H.H. Antibiotic resistance genes in water environment. Appl Microbiol Biotechnol. 82, 397, 2009.

6. BAQUERO F., MARTÍNEZ J.-L., CANTÓN R. Antibiotics and antibiotic resistance in water environments. Curr Opin Biotechnol. 19, 260, 2008.

7. PIOTROWSKA M., POPOWSKA M. The prevalence of antibiotic resistance genes among Aeromonas species in aquatic environments. Ann Microbiol. 64, 921, 2014.

8. PIOTROWSKA M., POPOWSKA M. Insight into the mobilome of Aeromonas strains. Front Microbiol. 6, 494, 2015.

9. KEMPER N. Veterinary antibiotics in the aquatic and terrestrial environment. Ecol Indic. 8, 1, 2008.

10. BÉRDY J. Bioactive microbial metabolites. J Antibiot (Tokyo). 58, 1, 2005.

11. DE LIMA PROCÓPIO R.E., DA SILVA I.R., MARTINS M.K., DE AZEVEDO J.L., DE ARAÚJO J.M. Antibiotics produced by Streptomyces. Braz J Infect Dis. 16, 466, 2 012.

12. PELAEZ F. The historical delivery of antibiotics from microbial natural products - can history repeat? Biochem Pharmacol. 71, 981, 2006.

13. GEBREYOHANNES G., MOGES F., SAHILE S., RAJA $\mathrm{N}$. Isolation and characterization of potential antibiotic producing actinomycetes from water and sediments of Lake Tana, Ethiopia. Asian Pac J Trop Biomed. 3, 426, 2013.

14. VALLI S., SUVATHI S.S., AYSHA O.S., NIRMALA P., VINOTH K.P., REENA A. Antimicrobial potential of Actinomycetes species isolated from marine environment. Asian Pac J Trop Biomed. 2, 469, 2012.

15. BARTON M.D. Impact of antibiotic use in the swine industry. Curr Opin Microbiol. 19, 9, 2014.

16. JI X., SHEN Q., LIU F., MA J., XU G., WANG Y., WU M. Antibiotic resistance gene abundances associated with antibiotics and heavy metals in animal manures and agricultural soils adjacent to feedlots in Shanghai; China. J Hazard Mater. 235, 178, 2012.

17. LU X.-M., LU P.-Z. Diversity, abundance, and spatial distribution of riverine microbial communities response to effluents from swine farm versus farmhouse restaurant. Appl Microbiol Biotechnol. 98, 7597, 2014.

18. KÜMMERER K. Resistance in the environment. J Antimicrob Chemother. 54, 311, 2004.

19. KWON J.-W. Mobility of veterinary drugs in soil with application of manure compost. Bull Environ Contam Toxicol. 87, 40, 2011.

20. THIELE-BRUHN S. Pharmaceutical antibiotic compounds in soils - a review. J Plant Nutr Soil Sci. 166, 145, 2003.

21. GOH E.-B., YIM G., TSUI W., MCCLURE J., SURETTE M.G., DAVIES J. Transcriptional modulation of bacterial gene expression by subinhibitory concentrations of antibiotics. Proc Natl Acad Sci. 99, 17025, 2002.

22. LAURETI L., MATIC I., GUTIERREZ A. Bacterial responses and genome instability induced by subinhibitory concentrations of antibiotics. Antibiotics. 2, 100, 2013.

23. LÓPEZ E., BLÁZQUEZ J. Effect of subinhibitory concentrations of antibiotics on intrachromosomal 
homologous recombination in Escherichia coli. Antimicrob Agents Chemother. 53, 3411, 2009.

24. OZ T., GUVENEK A., YILDIZ S., KARABOGA E., TAMER Y.T., MUMCUYAN N., OZAN V.B., SENTURK G.H., COKOL M., YEH P., TOPRAK E. Strength of selection pressure is an important parameter contributing to the complexity of antibiotic resistance evolution. Mol Biol Evol. msu 191, 2014.

25. ANDERSSON D.I., HUGHES D. Microbiological effects of sublethal levels of antibiotics. Nat Rev Microbiol. 12, 465, 2014.

26. MARTINEZ J.L., FAJARDO A., GARMENDIA L., HERNANDEZ A., LINARES J.F., MARTÍNEZ-SOLANO L., SÁNCHEZ M.B. A global view of antibiotic resistance. FEMS Microbiol Rev. 33, 44, 2009.

27. ALLEN H.K., DONATO J., WANG H.H., CLOUDHANSEN K.A., DAVIES J., HANDELSMAN J. Call of the wild: antibiotic resistance genes in natural environments. Nat Rev Microbiol. 8, 251, 2010.

28. MARTINEZ J.L. Environmental pollution by antibiotics and by antibiotic resistance determinants. Environ Pollut. 157, 2893, 2009.

29. MARTÍNEZ J.L., COQUE T.M., BAQUERO F. What is a resistance gene? Ranking risk in resistomes. Nat. Rev. Microbiol. 2014.

30. SALYERS A.A., AMABILE-CUEVAS C.F. Why are antibiotic resistance genes so resistant to elimination? Antimicrob Agents Chemother. 41, 2321, 1997.

31. DING C., HE J. Effect of antibiotics in the environment on microbial populations. Appl Microbiol Biotechnol. 87, 925, 2010.

32. POPOWSKA M., MIERNIK A., RZECZYCKA M., LOPACIUK A. The impact of environmental contamination with antibiotics on levels of resistance in soil bacteria. J Environ Qual. 39, 1679, 2010.

33. ZHANG L., LI X.-Z., POOLE K. Multiple antibiotic resistance in Stenotrophomonas maltophilia: involvement of a multidrug efflux system. Antimicrob Agents Chemother. 44, 287, 2000.

34. BARSZCZEWSKI J., KACA E., WOJDA R., The environmental conditions and production results in organic and conventional system of carp breeding. J Res Appl Agric Eng. $\mathbf{5 5}, 14,2010$.

35. MCCRADY M.H. The numerical interpretation of fermentation-tube results. J Infect Dis. 183, 1915.

36. LANE D.J. 16S/23S rRNA sequencing. Nucleic Acid Tech Bact Syst. 125, 1991.

37. PATTERSON A.J., COLANGELI R., SPIGAGLIA P., SCOTT K.P. Distribution of specific tetracycline and erythromycin resistance genes in environmental samples assessed by macroarray detection. Environ Microbiol. 9, 703, 2007.

38. CHELOSSI E., VEZZULLI L., MILANO A., BRANZONI M., FABIANO M., RICCARDI G., BANAT I.M. Antibiotic resistance of benthic bacteria in fish-farm and control sediments of the Western Mediterranean. Aquaculture. 219, 83, 2003.

39. KAWAHARA N., SHIGEMATSU K., MIYADAI T., KONDO R. Comparison of bacterial communities in fish farm sediments along an organic enrichment gradient. Aquaculture. 287, 107, 2009.

40. DEMING J.W., BAROSS J.A. The Early Diagenesis of Organic Matter: Bacterial Activity. In: Engel MH, Macko SA (eds) Org. Geochem. Springer US, pp 119-144 1993.

41. DEVARAJA T.N., YUSOFF F.M., SHARIFF M. Changes in bacterial populations and shrimp production in ponds treated with commercial microbial products. Aquaculture. 206, 245, 2002.

42. BRENNER D.J., KRIEG N.R., STALEY J.T. The Gammaproteobacteria. Bergey's Manual of Systematic Bacteriology. New York: Springer 2005.

43. BRENNER D.J., KRIEG N.R., STALEY J.T. Bergey's Manual of Systematic Bacteriology. Vol. Two, Part C, The A1pha-, Beta-, Delta-, and Epsilonproteobacteria. New York: Springer 2005.

44. GAO P., MAO D., LUO Y., WANG L., XU B., XU L. Occurrence of sulfonamide and tetracycline-resistant bacteria and resistance genes in aquaculture environment. Water Res. 46, 2355, 2012.

45. TAMMINEN M., KARKMAN A., LÕHMUS A., MUZIASARI W.I., TAKASU H., WADA S., SUZUKI S., VIRTA M. Tetracycline resistance genes persist at aquaculture farms in the absence of selection pressure. Environ Sci Technol. 45, 386, 2010.

46. SEYFRIED E.E., NEWTON R.J., RUBERT IV K.F., PEDERSEN J.A., MCMAHON K.D. Occurrence of tetracycline resistance genes in aquaculture facilities with varying use of oxytetracycline. Microb Ecol. 59, 799, 2010.

47. SHAH S.Q., COLQUHOUN D.J., NIKULI H.L., SØRUM $\mathrm{H}$. Prevalence of antibiotic resistance genes in the bacterial flora of integrated fish farming environments of Pakistan and Tanzania. Environ Sci Technol. 46, 8672, 2012.

48. AKINBOWALE O.L., PENG H., BARTON M.D. Antimicrobial resistance in bacteria isolated from aquaculture sources in Australia. J Appl Microbiol. 100, 1103, 2006.

49. SU H.-C., YING G.-G., TAO R., ZHANG R.-Q., FOGARTY L.R., KOLPIN D.W. Occurrence of antibiotic resistance and characterization of resistance genes and integrons in Enterobacteriaceae isolated from integrated fish farms in south China. J Environ Monit. 13, 3229, 2011.

50. BAKER-AUSTIN C., WRIGHT M.S., STEPANAUSKAS R., MCARTHUR J.V. Co-selection of antibiotic and metal resistance. Trends Microbiol. 14, 176, 2006.

51. SEILER C., BERENDONK T.U. Heavy metal driven coselection of antibiotic resistance in soil and water bodies impacted by agriculture and aquaculture. Front. Microbiol. 3: 2012.

52. BAQUERO F., ALVAREZ-ORTEGA C., MARTINEZ J.L. Ecology and evolution of antibiotic resistance. Environ Microbiol Rep. 1, 469, 2009.

53. MOHAPATRA H., MOHAPATRA S.S., MANTRI C.K., COLWELL R.R., SINGH D.V. Vibrio cholerae non-O1, non-O139 strains isolated before 1992 from Varanasi, India are multiple drug resistant, contain intSXT, dfr18 and aadA5 genes. Environ Microbiol. 10, 866, 2008.

54. ALONSO A., MARTÍNEZ J.L. Multiple antibiotic resistance in Stenotrophomonas maltophilia. Antimicrob Agents Chemother. 41, 1140, 1997.

55. AMINOV R.I. The role of antibiotics and antibiotic resistance in nature. Environ Microbiol. 11, 2970, 2009.

56. LAMBERT T., PLOY M.-C., DENIS F., COURVALIN P. Characterization of the Chromosomalaac (6')-Iz Gene of Stenotrophomonas maltophilia. Antimicrob Agents Chemother. 43, 2366, 1999.

57. AMINOV R.I., CHEE-SANFORD J.C., GARRIGUES N., TEFEREDEGNE B., KRAPAC I.J., WHITE B.A., MACKIE R.I. Development, validation, and application of PCR primers for detection of tetracycline efflux genes of gramnegative bacteria. Appl Environ Microbiol. 68, 1786, 2002.

58. CHEE-SANFORD J.C., AMINOV R.I., KRAPAC I.J., GARRIGUES-JEANJEAN N., MACKIE R.I. Occurrence and diversity of tetracycline resistance genes in lagoons and 
groundwater underlying two swine production facilities. Appl Environ Microbiol. 67, 1494, 2001.

59. LEE Y.J., HAN H.S., SEONG C.N., LEE H.Y., JUNG J.S. Distribution of genes coding for aminoglycoside acetyltransferases in gentamicin resistant bacteria isolated from aquatic environment. J Microbiol. 36, 249, 1998.

60. CANTAS L., SHAH S.Q.A., CAVACO L.M., MANAIA C.M., WALSH F., POPOWSKA M., GARELICK H., BÜRGMANN H., SØRUM H. A brief multi-disciplinary review on antimicrobial resistance in medicine and its linkage to the global environmental microbiota. Front Microbiol. 4, 96, 2013.
61. PEREIRA A., SANTOS A., TACÃO M., ALVES A., HENRIQUES I., CORREIA A. Genetic diversity and antimicrobial resistance of Escherichia coli from Tagus estuary (Portugal). Sci Total Environ. 461, 65, 2013.

62. ROBERTS M.C. Mechanisms of bacterial antibiotic resistance and lessons learned from environmental tetracycline resistant bacteria. John Wiley \& Sons, Inc., Hoboken, New Jersey 2012. 